\title{
Atom Probe Tomography Study of Fe Segregation at Phase Interface in $\mathrm{Zr}-2.5 \mathrm{Nb}$ Alloy
}

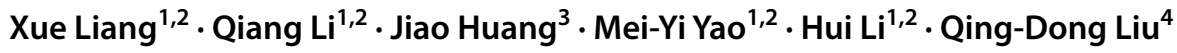

Received: 8 April 2019 / Revised: 20 May 2019 / Published online: 19 June 2019

(C) The Chinese Society for Metals (CSM) and Springer-Verlag GmbH Germany, part of Springer Nature 2019

\begin{abstract}
$\beta$ - $\mathrm{Nb}$ is a typical second phase in $\mathrm{Zr}-\mathrm{Nb}$-based alloys used as fuel claddings in water-cooled nuclear reactors. The segregation of alloying element $\mathrm{Fe}$ may affect the corrosion resistance of $\mathrm{Zr}-\mathrm{Nb}$-based alloys. In this work, the Fe segregation at the interface between $\beta$ - $\mathrm{Nb}$ phase and $\alpha-\mathrm{Zr}$ matrix in $\mathrm{Zr}-2.5 \mathrm{Nb}$ alloy was studied using atom probe tomography and focused ion beam. The results suggested that the Fe concentration was much lower than $\mathrm{Nb}$ concentration in $\alpha-\mathrm{Zr}$ matrix, while $\mathrm{Fe}$ selectively segregated at the $\beta-\mathrm{Nb} / \alpha-\mathrm{Zr}$ phase interface, leading to a Fe concentration peak at some interfaces. The peak Fe concentration varied from 0.4 to 1.2 at.\% and appeared at the position where $\mathrm{Zr}$ concentration was approximately equal to $\mathrm{Nb}$ concentration. The selective segregation of Fe should be affected by the heat treatment and structure defects induced by cold rolling.
\end{abstract}

Keywords $\mathrm{Zr}-\mathrm{Nb}$ alloy $\cdot \beta$ - $\mathrm{Nb}$ phase $\cdot$ Phase interface $\cdot$ Segregation $\cdot$ Atom probe tomography

\section{Introduction}

$\mathrm{Zr}$ alloys have been widely used as structural materials (e.g., fuel cladding) of reactor pressure vessel (RPV) in light water reactors due to their low thermal neutron penalty, desired mechanical property and high corrosion resistance. The waterside corrosion of $\mathrm{Zr}$ alloys in RPV is known to directly affect the structure integrity of the relevant components. However, the underlying corrosion mechanism of $\mathrm{Zr}$ alloys still remains unclear as the corrosion process in high-temperature water is dominated by multiple factors. The secondary phases and the trace alloying elements in the alloy matrix play a key role in the corrosion process.

Available online at http://link.springer.com/journal/40195

Xue Liang

liangxue@shu.edu.cn

1 Institute of Materials, Shanghai University, Shanghai 200072, China

2 Laboratory for Microstructures, Shanghai University, Shanghai 200444, China

3 School of Materials Science and Engineering, Inner Mongolia University of Technology, Hohhot 010051, China

4 School of Nuclear Science and Engineering, Shanghai Jiaotong University, Shanghai 200240, China
The $\mathrm{Zr}-\mathrm{Nb}$ alloy is a promising candidate material for fuel cladding in pressurized water reactors due to the low thermal neutron penalty and strengthening effect of $\mathrm{Nb}$. The corrosion resistance of $\mathrm{Zr}-\mathrm{Nb}$ alloy is closely related to the solubility of $\mathrm{Nb}$ and the oxidation of $\beta$ - $\mathrm{Nb}$ phase in $\alpha-\mathrm{Zr}$ matrix [1]. The equilibrium solid solubility of $\mathrm{Nb}$ in $\alpha-\mathrm{Zr}$ matrix of $\mathrm{Zr}-\mathrm{Nb}$ binary alloy is $0.2-0.3 \mathrm{wt} \%$ [2-4]. It was reported that the $\mathrm{Zr}-\mathrm{Nb}$ binary alloy with the $\mathrm{Nb}$ content at this equilibrium solid solubility exhibited the best corrosion resistance, while the supersaturation of $\mathrm{Nb}$ in $\alpha-\mathrm{Zr}$ matrix accelerated the corrosion process [3-6]. Generally, the $\mathrm{Nb}$ supersaturation leads to precipitation of $\beta$ - $\mathrm{Nb}$ phase, in which the $\mathrm{Nb}$ concentration is higher than 80 at.\% [7, 8]. As a typical second phase in $\mathrm{Zr}-\mathrm{Nb}$ alloy, $\beta$ - $\mathrm{Nb}$ precipitates retarded the corrosion process in deionized water, endowing the commercial $\mathrm{Zr}-2.5 \mathrm{Nb}$ alloy with excellent corrosion resistance even under irradiation condition [4-6]. On the other hand, previous studies revealed that the oxidation of $\beta$ $\mathrm{Nb}$ particles enhanced the corrosion of $\mathrm{Zr}-\mathrm{Nb}$ alloy in lithiated water or dissolved oxygen environment [9]. The role of $\beta-\mathrm{Nb}$ precipitates is susceptible to the water chemistry.

The interactions between the alloying elements could affect the maximum solid solubility of $\mathrm{Nb}$ and $\beta-\mathrm{Nb}$ precipitation in $\alpha-\mathrm{Zr}$ matrix $[4,10]$. A small amount of Fe was reported to increase the $\mathrm{Nb}$ solid solubility to $0.29-0.49 \mathrm{wt} \%$ and inhibit the $\beta-\mathrm{Nb}$ precipitation [3]. Therefore, Fe may 
affect the corrosion process through altering the maximum solubility of $\mathrm{Nb}$ and the kinetics of $\beta$ - $\mathrm{Nb}$ precipitation. Recently, researchers have investigated the chemistry inhomogeneity of $\mathrm{Sn}, \mathrm{Ni}$ and $\mathrm{Fe}$ at the grain boundary and its effect on the oxidation process [11-13]. Fe and Ni segregation at the grain boundary was thought to be associated with the enhancement of hydrogen pickup by $\mathrm{Zr}-2.5 \mathrm{Nb}$ alloy [11]. Metallic Sn particles with a size up to $20 \mathrm{~nm}$ were found to accelerate the corrosion process in surrounding $\mathrm{Zr}-2$ matrix due to the fact that $\mathrm{Sn}$ depletion in the surrounding $\mathrm{ZrO}_{2}$ grains could lead to transformation of chemically stabilized tetragonal phase to monoclinic $\mathrm{ZrO}_{2}$ [12]. The segregation and clustering of $\mathrm{Fe}$ and $\mathrm{Sn}$ at the grain boundary in the $\mathrm{Zr}-2$ alloy were also reported to have implications with the waterside corrosion kinetics of the alloy $[14,15]$. However, little attention was paid to the distribution of $\mathrm{Nb}$ and $\mathrm{Fe}$ and the relationship between the element distribution and $\beta$ - $\mathrm{Nb}$ phase in $\mathrm{Zr}-\mathrm{Nb}$ alloy. In addition, the alloying element content in $\mathrm{Zr}$ alloys is quite low, leading to a difficulty of precise examination of the alloying element. For example, the Fe solubility in $\mathrm{Zr}-\mathrm{Sn}-\mathrm{Nb}-\mathrm{Fe}$ alloy determined by electron probe was $(0.1 \pm 0.3)$ at.\%, which was quite different from that calculated based on the $\mathrm{Zr}-\mathrm{Sn}-\mathrm{O}$ phase diagram (0.12 at.\%) [16, 17]. The difference would be larger if there is segregation or clustering of $\mathrm{Fe}$ in the matrix. Therefore, accurate analysis of $\mathrm{Fe}$ distribution in $\mathrm{Zr}-\mathrm{Nb}$ alloy is necessary.

The atom probe tomography (APT) is known for the high atomic scale resolution and the good chemistry sensitivity in three dimensions (3D) [18]. In this work, the 3D distribution of $\mathrm{Zr}, \mathrm{Nb}$ and $\mathrm{Fe}$ in bulk $\mathrm{Zr}-2.5 \mathrm{Nb}$ alloy was investigated using APT, in order to clarify the relationship between $\mathrm{Fe}$ segregation and $\beta$ - $\mathrm{Nb}$ phase.

\section{Experimental}

The material used in this study was $\mathrm{Zr}-2.5 \mathrm{Nb}$ alloy plate with a thickness of $1.4 \mathrm{~mm}$, which was supplied by the Northwest Institute for Non-ferrous Metal Research. The plate was homogenized at $1030{ }^{\circ} \mathrm{C}$ for $40 \mathrm{~min}$; then, it was cold rolled to about $0.7 \mathrm{~mm}$, followed by an annealing treatment at $580{ }^{\circ} \mathrm{C}$ for $5 \mathrm{~h}$. The chemical composition of the $\mathrm{Zr}-2.5 \mathrm{Nb}$ alloy was determined to be $2.5 \% \mathrm{Nb}, 0.012 \% \mathrm{Fe}$, $0.008 \% \mathrm{Cr}$ and $\mathrm{Zr}$ balance (wt $\%$ ), using inductively coupled plasma atomic emission spectrometry. The microstructure was examined by a JEM-2010F transmission electron microscope (TEM).

The needle-tip specimen for APT analysis was fabricated using a FEI 600i focused ion beam (FIB) instrument according to the lift-out method [19]. Figure 1 shows the detailed fabrication process of the APT specimen. It is worth mentioning that $\mathrm{Pt}$ was previously deposited as a protective layer. At the last milling stage, a small energy of $2 \mathrm{keV}$ was used to remove the remaining $\mathrm{Pt}$ and to minimize the irradiation damage of $\mathrm{Ga}$ ions. A tip size of no more than $50 \mathrm{~nm}$ was finally obtained for all APT specimens.

The accurate chemical composition analysis was performed by using a CAMECA LEAP-4000X HR APT system which operated in a local electronic atom probe and
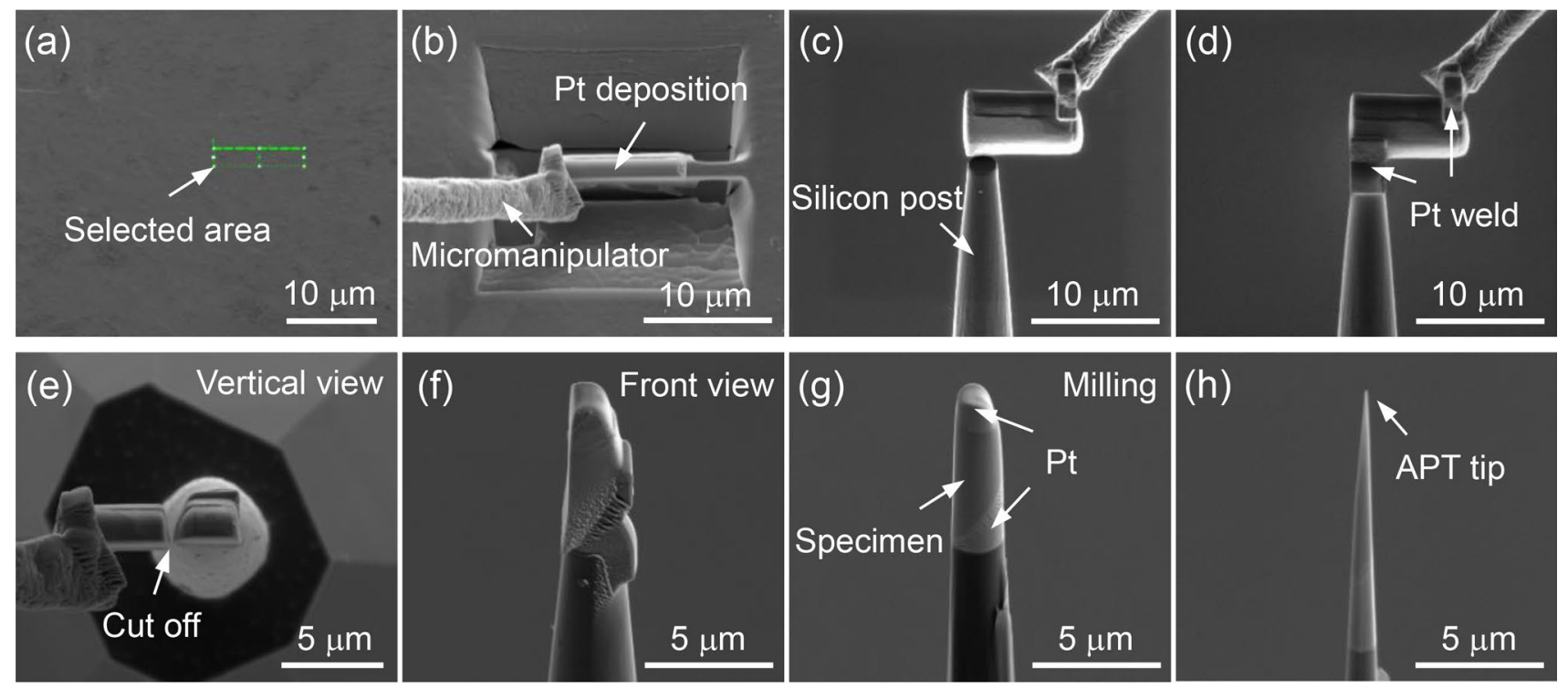

Fig. 1 Fabrication process of APT specimen by using FIB: a select an area of $10 \mu \mathrm{m} \times 2 \mu \mathrm{m}$ on the surface; $\mathbf{b}$ isolate the volume, weld it to a micromanipulator and lift it out; $\mathbf{c}$ move the volume to a silicon post; $\mathbf{d}$ weld the volume to the silicon post; $\mathbf{e}, \mathbf{f}$ cut off the volume with the micromanipulator; $\mathbf{g}$ milling stage; $\mathbf{h}$ cleaning-up to finish the fabrication of APT tip 
laser pulsing mode. To avoid the rupture of the APT specimen, a pulse repetition rate of $200 \mathrm{kHz}$ and a laser energy of 70-100 pJ were used [18]. During the APT test, the temperature of the specimens was maintained at $\sim 50 \mathrm{~K}$ while the standing voltage varied automatically to maintain a detection rate of 0.005 ion/pulse. The collected APT data were reconstructed and analyzed using the IVAS 3.6.8 software. The default value of the image compression factor was set as 3.3, and the evaporation field of $\mathrm{Zr}$ was $28 \mathrm{~V} / \mathrm{nm}$ [20] for the APT data reconstruction.

\section{Results and Discussion}

The TEM micrograph of the $\mathrm{Zr}-2.5 \mathrm{Nb}$ alloy sheet is shown in Fig. 2, which is consisted of partially recrystallized $\alpha-\mathrm{Zr}$ matrix and a dispersion of fine precipitates. The numerous spherical precipitates were detected as $\beta$ - $\mathrm{Nb}$ phase, while the rod-like ones with a small amount were identified to be residual $\beta-\mathrm{Zr}$ phase. The $\beta$ - $\mathrm{Nb}$ and $\beta$ - Zr phases are common precipitates in $\mathrm{Zr}-2.5 \mathrm{Nb}$ alloy [8].

Figure 3 shows the reconstructed atom maps of $\mathrm{Zr}, \mathrm{Nb}$ and $\mathrm{Fe}$ in the $\mathrm{Zr}-2.5 \mathrm{Nb}$ alloy sheet. No second phase precipitates or clusters were detected in this APT dataset. All the elements were homogeneously distributed. The $\mathrm{Nb}$ content in the $\alpha$-Zr matrix was determined as approximately 0.67 at. $\%$.

Figure 4 shows the reconstructed atom maps of $\mathrm{Zr}$, $\mathrm{Nb}$ and $\mathrm{Fe}$ in the $\mathrm{Zr}-2.5 \mathrm{Nb}$ alloy sheet from different regions of interest, which clearly shows the Fe segregation (Fig. 4b) and $\mathrm{Nb}$-enriched clusters (Fig. 4c). These clusters were defined as $\beta$ - Nb precipitates under TEM observation (Fig. 2). For a better visualization, the $\beta$ - $\mathrm{Nb}$ precipitates are surrounded by the 80 at. $\% \mathrm{Nb}$

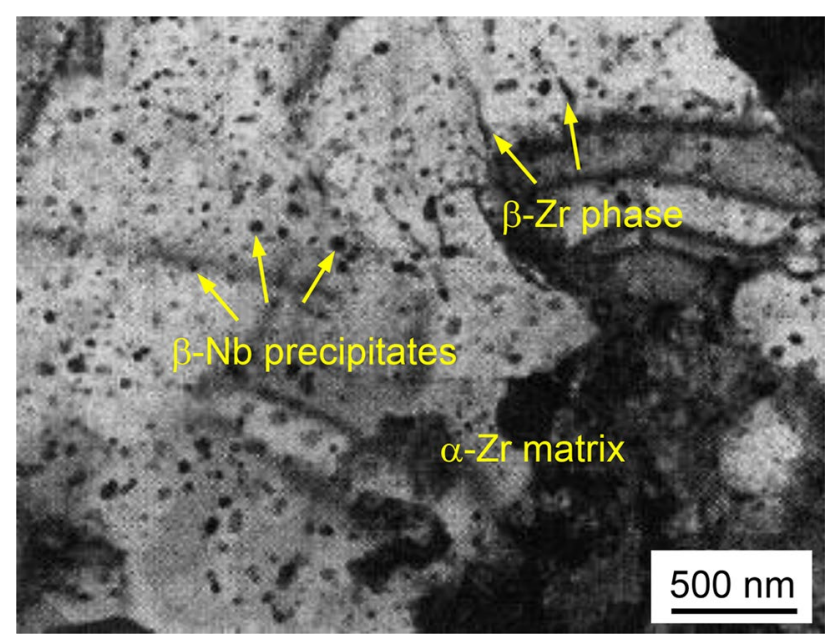

Fig. 2 TEM micrograph of $\mathrm{Zr}-2.5 \mathrm{Nb}$ alloy showing spherical $\beta$ - Nb precipitates and rod-like $\beta$ - $\mathrm{Zr}$ phase in the $\alpha$ - $\mathrm{Zr}$ matrix
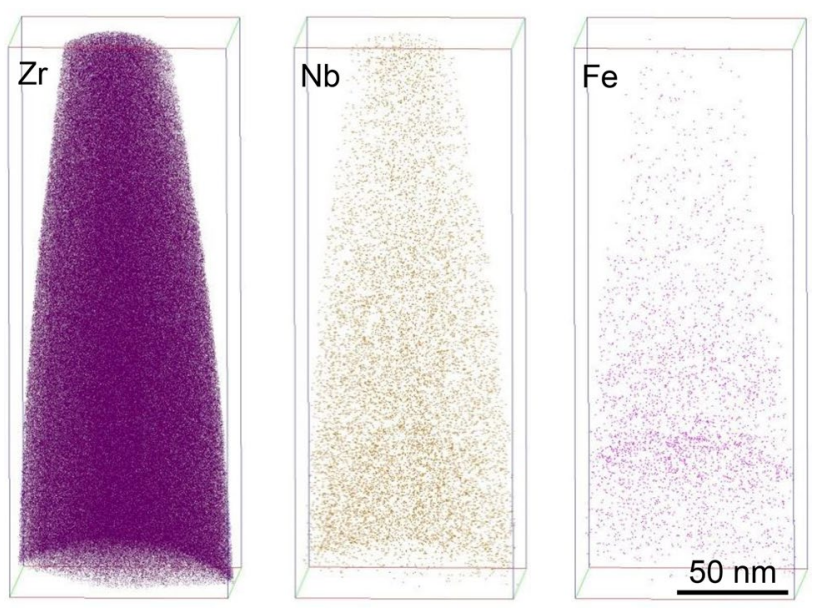

Fig. 3 APT reconstructed atom maps of $\mathrm{Zr}, \mathrm{Nb}$ and $\mathrm{Fe}$ in the $\mathrm{Zr}-$ $2.5 \mathrm{Nb}$ alloy, showing homogeneous distribution of $\mathrm{Zr}, \mathrm{Nb}$ and $\mathrm{Fe}$ atoms. The size of the volume analyzed is $114 \mathrm{~nm} \times 113 \mathrm{~nm} \times 289 \mathrm{~nm}$

iso-concentration surface (Fig. 4d). Figure $4 \mathrm{~b}$ and d shows that the $\mathrm{Fe}$ atoms appeared to segregate at the interface between the $\beta$-Nb precipitates and the $\alpha$ - $\mathrm{Zr}$ matrix (i.e., $\beta-\mathrm{Nb} / \alpha-\mathrm{Zr}$ phase interface). The proxigram profiles corresponding to two $\beta$-Nb precipitates (P1 and $\mathrm{P} 3$ ) marked in Fig. 4d are shown in Fig. 4e, f. The results indicated that the $\mathrm{Nb}$ content in most $\beta-\mathrm{Nb}$ precipitates was close to 100 at.\%, which is consistent with the result of above 80 at.\% reported in Ref. [5]. In addition, $\mathrm{Fe}$ atoms were detected to segregate at the $\beta-\mathrm{Nb} / \alpha-\mathrm{Zr}$ phase interface, resulting in a concentration peak of $\mathrm{Fe}$ at the phase interface. The peak concentration of Fe varied from 0.4 to 1.2 at.\% for different precipitates. Further, the concentration peak of $\mathrm{Fe}$ appeared at the position where the $\mathrm{Zr}$ content was approximately equal to $\mathrm{Nb}$ content. The $\mathrm{Fe}$ contents at the positions far away from the $\beta-\mathrm{Nb}$ precipitates were much lower, which is consistent with the results shown in Fig. 3.

Figure 5 shows the reconstructed atom maps of $\mathrm{Nb}$ and $\mathrm{Fe}$ and proxigram from the third APT dataset. $\mathrm{Nb}$-enriched clusters (i.e., $\beta$-Nb phase) were observed in Fig. 5a. Slight $\mathrm{Fe}$ segregation was also found at the $\beta-\mathrm{Nb} / \alpha-\mathrm{Zr}$ interfaces in Fig. 5b, c. Nevertheless, the magnitude of Fe segregation was weak with the peak $\mathrm{Fe}$ concentration of less than 0.1 at. \%, as shown in Fig. 5d. This result indicated that not all the $\beta-\mathrm{Nb} / \alpha-\mathrm{Zr}$ phase interfaces were obviously enriched with $\mathrm{Fe}$ and the $\mathrm{Fe}$ segregation at the $\beta$ - $\mathrm{Nb} / \alpha-\mathrm{Zr}$ phase interfaces was selective.

Figure 6 shows the interface structure between the large $\beta$ - $\mathrm{Nb}$ phase and $\alpha$ - $\mathrm{Zr}$ matrix in the $\mathrm{Zr}-2.5 \mathrm{Nb}$ alloy. Obvious lattice distortion and mismatch at the interface was found in the high-resolution transmission electron microscopy (HRTEM) image, which is a kind of structure defect induced by cold rolling. 

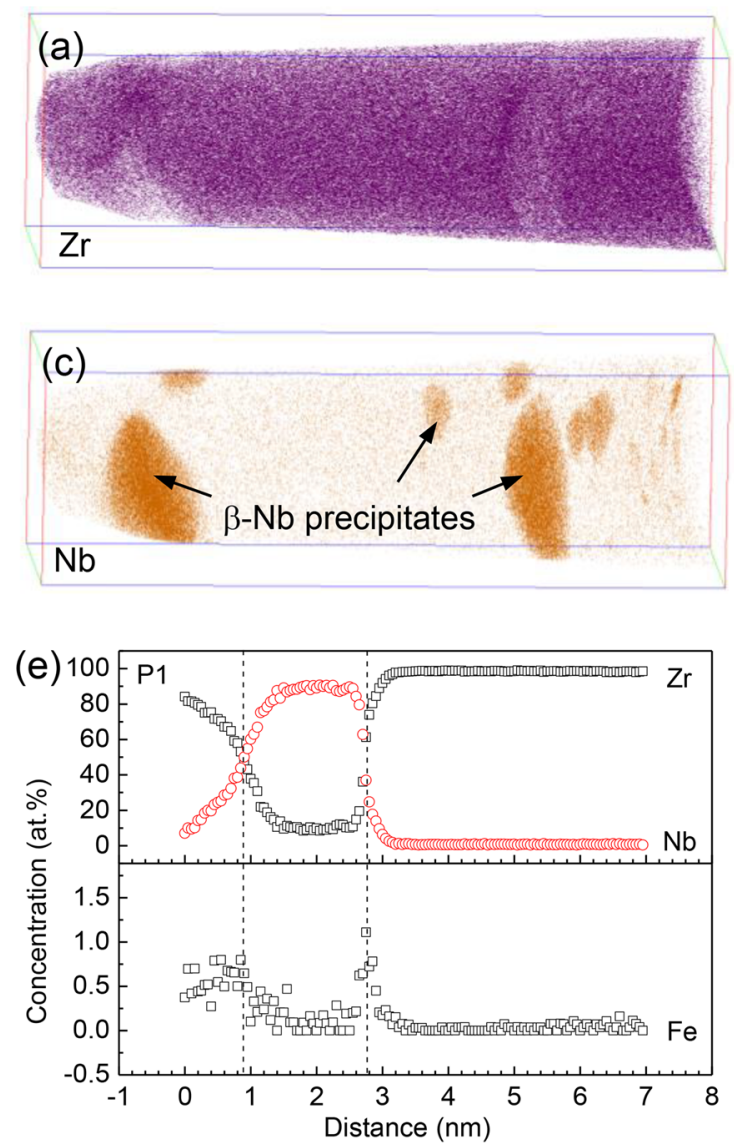
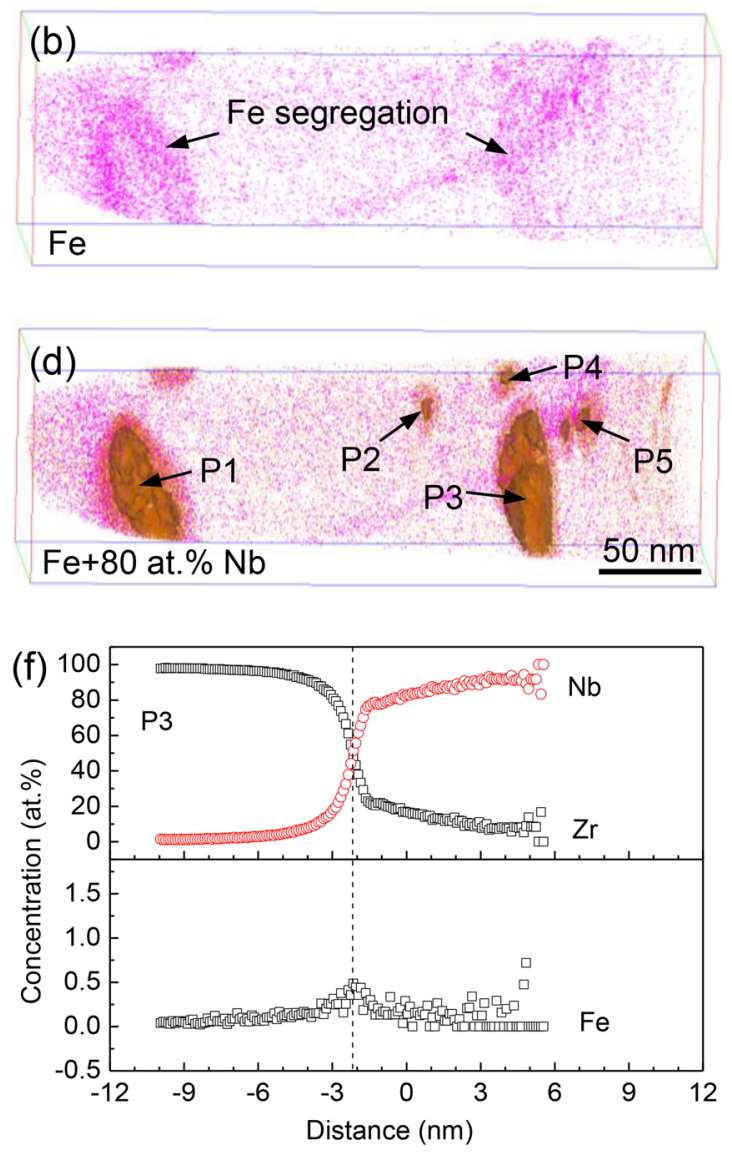

Fig. 4 a-c APT reconstructed atom maps of $\mathrm{Zr}, \mathrm{Fe}$ and $\mathrm{Nb}$ in the $\mathrm{Zr}-2.5 \mathrm{Nb}$ alloy, showing $\mathrm{Fe}$ segregation and $\beta$ - $\mathrm{Nb}$ precipitates in the matrix. The size of the volume analyzed is $90 \times 88 \times 284 \mathrm{~nm}^{3}$, $\mathbf{d}$ Fe atom map and 80 at.\% Nb iso-concentration surface. All the precipitates are marked by arrows, e, $\mathbf{f}$ proxigram profiles for $\mathrm{Zr}, \mathrm{Nb}$ and $\mathrm{Fe}$ of two selected $\beta$ - $\mathrm{Nb}$ precipitates (P1 and $\mathrm{P} 3$, respectively) shown in $\mathbf{d}$

The APT results shown in Figs. 3, 4 and 5 suggested that not all the $\beta-\mathrm{Nb} / \alpha-\mathrm{Zr}$ phase interfaces were obviously enriched with $\mathrm{Fe}$. The selective segregation of Fe was likely to dependent on the heat treatment. Following the homogenization annealing at $1030{ }^{\circ} \mathrm{C}$ for $40 \mathrm{~min}$, uniform $\beta$ - $\mathrm{Zr}$ phase was formed in the $\mathrm{Zr}-2.5 \mathrm{Nb}$ alloy. At the slow cooling stage of the homogenization annealing, some $\beta$ - $\mathrm{Zr}$ phases decomposed to form the $\beta-\mathrm{Nb}$ precipitates (i.e., proeutectoid $\beta-\mathrm{Nb}$ phase). Subsequent cold rolling and annealing treatment induced dense structure defects around these $\beta$ - $\mathrm{Nb}$ particles (Fig. 6). Therefore, these $\beta$-Nb particles were easier to grow up due to the accelerated diffusion rate of solute atoms by the structure defect. In addition to the proeutectoid $\beta-\mathrm{Nb}$ phase, eutectoid $\beta$-Nb phase was formed by the decomposition of $\beta$ - Zrr phase into $\alpha$ - Zr matrix and $\beta$ - $\mathrm{Nb}$ phase following the annealing treatment at $580{ }^{\circ} \mathrm{C}$. With consideration to the results shown in Figs. 4 and 5, obvious Fe segregation occurred at the interfaces between the larger $\beta$ - $\mathrm{Nb}$ particles (P1 and P3) and the $\alpha-\mathrm{Zr}$ matrix rather than those between the smaller particles (P7) and matrix. This result indicated that $\mathrm{Fe}$ tended to segregate at the interface between the proeutectoid $\beta$-Nb phase and the $\alpha$-Zr matrix. According to the study reported by Sundell et al. [16], the degree of $\mathrm{Fe}$ segregation was higher in the deformed $\mathrm{Zr}-2.5 \mathrm{Nb}$ alloy. In addition, Toyama et al. [21] reported that Fe segregation occurred at the structure defects around the precipitates in $\mathrm{Zr}-\mathrm{Nb}$ alloy. These two studies demonstrated that the crystal structure defect in the $\mathrm{Zr}-2.5 \mathrm{Nb}$ alloy matrix played a key role in the Fe segregation. Therefore, in addition to the heat treatment, the effect of cold rolling on $\mathrm{Fe}$ segregation in the $\mathrm{Zr}-2.5 \mathrm{Nb}$ alloy cannot be neglected.

\section{Conclusions}

(1) $\mathrm{Nb}$ content in $\alpha$ - $\mathrm{Zr}$ matrix was about 0.67 at. $\%$ while Fe content was much lower in $\alpha$ - $\mathrm{Zr}$ matrix.

(2) Fe was found to segregate at the $\beta-\mathrm{Nb} / \alpha-\mathrm{Zr}$ phase interface, leading to a concentration peak of $\mathrm{Fe}$. The peak Fe concentration varied from 0.4 to 1.2 at. \%, which appeared at the position where $\mathrm{Zr}$ content was approximately equal to $\mathrm{Nb}$ content. 

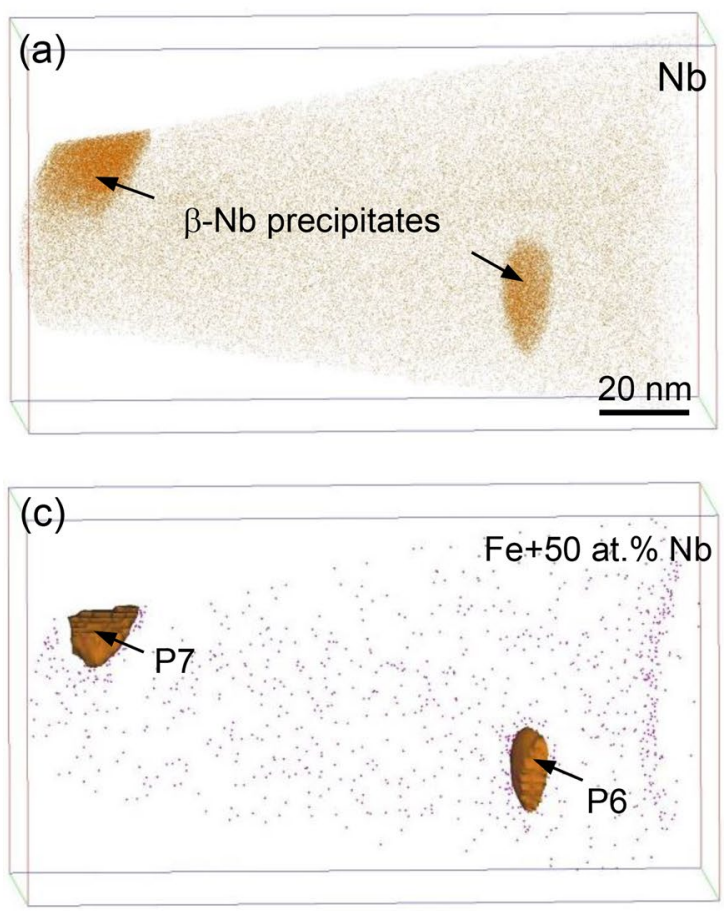

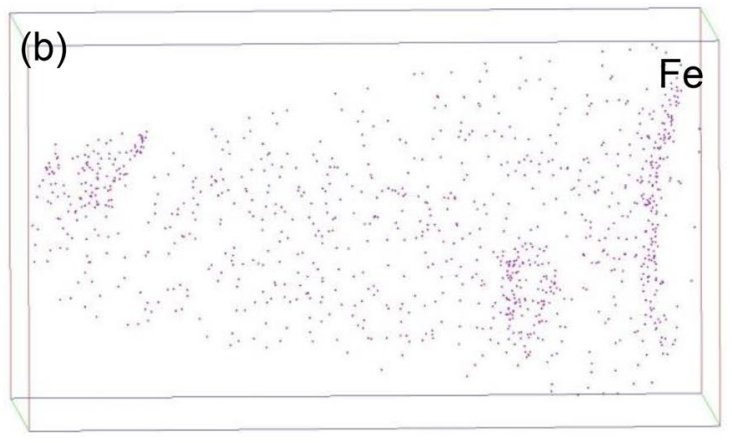

(d)

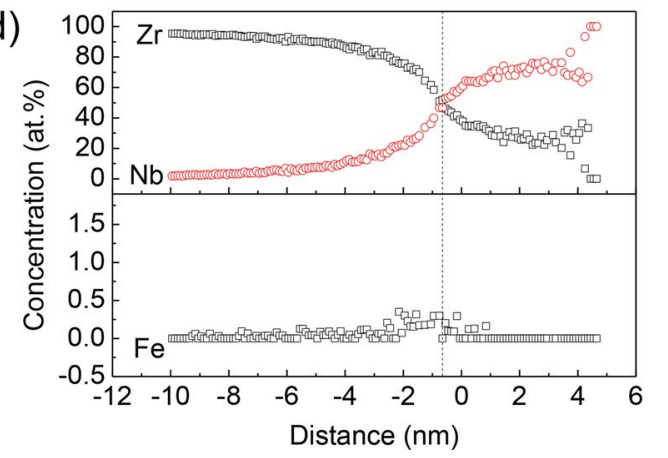

Fig. 5 a, b APT reconstructed atom maps of $\mathrm{Nb}$ and $\mathrm{Fe}$ in the $\mathrm{Zr}-2.5 \mathrm{Nb}$ alloy, $\mathbf{c} 50$ at.\% $\mathrm{Nb}$ iso-concentration surface showing $\beta$ - $\mathrm{Nb}$ precipitates, $\mathbf{d}$ proxigram profiles for $\mathrm{Zr}, \mathrm{Nb}$ and $\mathrm{Fe}$ of the $\beta$-Nb precipitates marked by $\mathrm{P} 7$ in $\mathbf{c}$

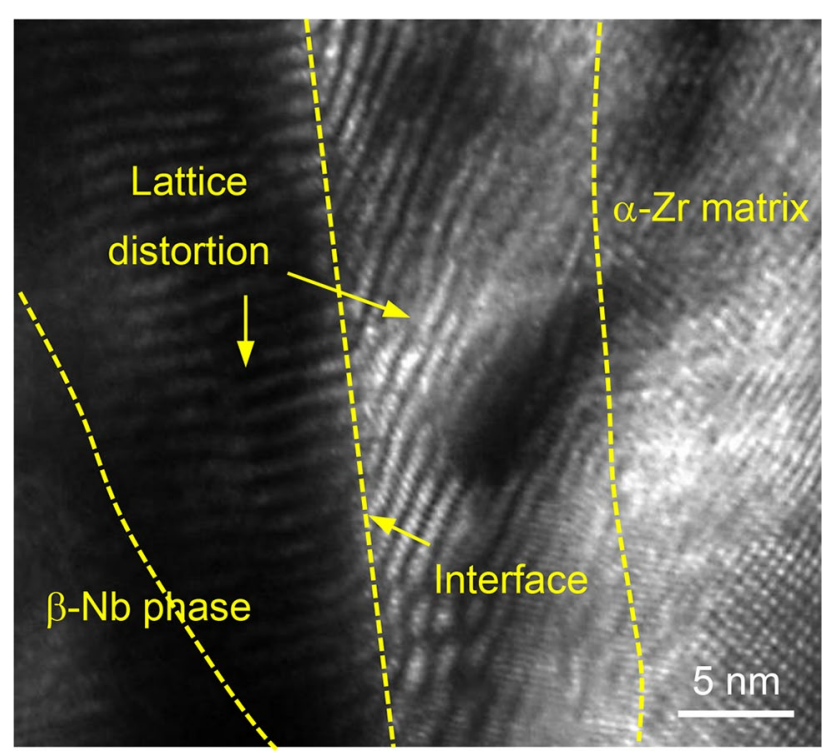

Fig. 6 HRTEM image of interface structure between the large $\beta-\mathrm{Nb}$ phase and $\alpha$ - $\mathrm{Zr}$ matrix in the $\mathrm{Zr}-2.5 \mathrm{Nb}$ alloy

(3) Not all the $\beta-\mathrm{Nb} / \alpha-\mathrm{Zr}$ phase interfaces were obviously enriched with Fe. The selective segregation of Fe was likely to be affected by the heat treatment and the structure defects induced by cold rolling.
Acknowledgements This work was supported by the National Natural Science Foundation of China (No. 51171102). The authors are grateful to Prof. Wenqing Liu and Prof. Pengfei Hu in Laboratory for Microstructures of Shanghai University for their assistance in the microstructural analysis.

\section{References}

[1] Q. Li, X. Liang, J.C. Peng, R.D. Liu, K. Yu, B.X. Zhou, Acta Metall. Sin. (in Chinese) 47, 893 (2011)

[2] H.G. Kim, S.Y. Park, M.H. Lee, Y.H. Jeong, S.D. Kim, J. Nucl. Mater. 373, 429 (2008)

[3] Y.H. Jeong, H.G. Kim, T.H. Kim, J. Nucl. Mater. 317, 1 (2003)

[4] Y.H. Jeong, H.G. Kim, D.J. Kim, B.K. Choi, J.H. Kim, J. Nucl. Mater. 323, 72 (2003)

[5] O.T. Woo, G.M. Mcdougall, R.M. Hutcheon, V.F. Urbanic, M. Griffiths, C.E. Coleman, Corrosion of electron-irradiated $\mathrm{Zr}$ $2.5 \mathrm{Nb}$ and Zircaloy-2. Paper Presented at the Zirconium in the Nuclear Industry: Twelfth International Symposium, Toronto, Canada, 15-18 June 2000

[6] F.U. Vincent, M. Griffiths, Microstructural aspects of corrosion and hydrogen ingress in $\mathrm{Zr}-2.5 \mathrm{Nb}$. Paper Presented at the Zirconium in the Nuclear Industry: Twelfth International Symposium, Toronto, Canada, 15-18 June 2000

[7] H.G. Kim, J.Y. Park, Y.H. Jeong, J. Nucl. Mater. 347, 140 (2005)

[8] G.P. Sabol, R.J. Comstock, U.P. Nayak, Effect of dilute alloy additions of molybdenum niobium and vanadium on zirconium corrosion. Paper Presented at the Zirconium in the Nuclear Industry: Twelfth International Symposium, Toronto, Canada, 15-18 June 2000 
[9] J. Huang, M.Y. Yao, C.Y. Gao, P.F. Hu, X. Liang, J.L. Zhang, B.X. Zhou, Q. Li, E. Ahsan, Corros. Sci. 104, 269 (2016)

[10] Q. Li, X. Liang, J.C. Peng, K. Yu, M.Y. Yao, B.X. Zhou, Acta Metall. Sin. (in Chinese) 47, 877 (2011)

[11] G. Sundell, M. Thuvander, H.O. Andrén, Corros. Sci. 102, 490 (2016)

[12] G. Sundell, M. Thuvander, H.O. Andrén, J. Nucl. Mater. 456, 409 (2015)

[13] N. Ni, D. Hudson, J. Wei, P. Wang, S. Lozano-Perez, G.D.W. Smith, J.M. Sykes, S.S. Yardley, K.L. Moore, S. Lyon, R. Cottis, M. Preuss, C.R.M. Grovenor, Acta Mater. 60, 7132 (2012)

[14] G. Sundell, M. Thuvander, H.O. Andrén, Corros. Sci. 65, 10 (2012)

[15] M. Thuvander, H.O. Andren, Ultramicroscopy 111, 711 (2011)
[16] N. Nieva, D. Arias, J. Nucl. Mater. 359, 29 (2006)

[17] D. Charquet, R. Hahn, E. Ortlieb, J.P. Gros, J.E. Wadier, Solubility limit and formation of intermetallic precipitates in $\mathrm{ZrSnFeCr}$ alloys. Paper Presented at the Zirconium in the Nuclear Industry: Eighth International Symposium, San Diego, California, US, 19-23 June 1988

[18] Q.D. Liu, Y.H. Chen, C.W. Li, J.F. Gu, Acta Metall. Sin. (Engl. Lett.) 31, 465 (2018)

[19] K. Thompson, D. Lawrence, D.J. Larson, J.D. Olson, T.F. Kelly, B. Gorman, Ultramicroscopy 107, 131 (2007)

[20] T.T. Tsong, Y.S. Ng, A.J. Melmed, Surf. Sci. 77, L187 (1978)

[21] T. Toyama, Y. Matsukawa, K. Saito, Y. Satoh, H. Abe, Y. Shinohara, Y. Nagai, Scr. Mater. 108, 156 (2015) 